\title{
Leak Detection and Repair (LDAR) Standard Review for Self-Inspection and Management for VOC Emission in China's Traditional Energy Chemical Industry
}

\author{
Jinbo Zhao*, Ming Chen \\ State Key Laboratory of Water Environment Simulation, School of Environment, Beijing Normal University, Beijing, China \\ Email: *henryzjo@bnu.edu.cn
}

How to cite this paper: Zhao, J.B. and Chen, M. (2018) Leak Detection and Repair (LDAR) Standard Review for Self-Inspection and Management for VOC Emission in China's Traditional Energy Chemical Industry. Journal of Environmental Protection, 9, 1155-1170.

https://doi.org/10.4236/jep.2018.911072

Received: July 17, 2018

Accepted: October 19, 2018

Published: October 22, 2018

Copyright $\odot 2018$ by authors and Scientific Research Publishing Inc. This work is licensed under the Creative Commons Attribution International License (CC BY 4.0).

http://creativecommons.org/licenses/by/4.0/

\begin{abstract}
The emission of the traditional energy chemical industry accounts for $20 \%$ of the total man-made VOC emission in China, of which coal chemical and petrochemical plants are one of the most important VOC emission sources. VOC emission sources mainly include the leakage of oil refinery units and equipment, pipes and valves, respiration and leakage of various types of storage tanks, effusion of oils during loading and unloading, effusion of sewage treatment systems, all kinds of process tail gas, etc. In this paper, the current management status of VOC emission in China's coal chemical industry and petrochemical industry are analyzed, which divides VOC management into intentional and fugitive emission. The Leak Detection and Repair (LDAR) management method and technology for equipment, pipes and valves implemented in the United States are studied to propose self-inspection management methods and measures for VOC emissions in the energy chemical industry, providing strategies and recommendations for energy conservation, emission reduction and cleaner production in the traditional energy chemical industry.
\end{abstract}

\section{Keywords}

Self-Inspection, VOC, China’s Traditional Energy Chemical Industry

\section{Introduction}

With the rapid economic development, China's energy demand grows rapidly, posing a great challenge to energy supply and environmental ecology. Petroleum resources are increasingly scarce, and the international and domestic oil prices 
are continuously increased in the long term, causing a series of energy security issues. China's fossil energy structure is rich in coal and poor in oil \& gas. In 2014, China ranks third in the world in proven reserves of coal [1] [2]. The adoption of advanced coal conversion technology to build a new coal chemical industry with cleaner environment, significant economic benefits, leading products that are liquid fuels and petrochemicals which can replace petroleum are important ways to solve or alleviate energy shortages in China [3].

At the same time, the development of the coal chemical industry is important to the adjustment of the industrial structure, product structure of coal-producing regions, the enhancement of core competence of enterprises and the realization of sustainable development [4]. Therefore, the coal chemical industry in China is developing vigorously with the encouragement of national policies, the guidance of the government and the active participation of enterprises. Large-scale and purposeful development of the coal chemical industry can make good use of limited coal resources to solve many energy crises. The coal chemical industry faces new market demands and development opportunities in China.

Coal chemical and petrochemical production processes can be generated a large number of pollutants [5], mainly volatile organic compounds (VOCs). By the definition of the US Environmental Protection Agency (USEPA), VOCs are organic compounds with a vapor pressure of $13.33 \mathrm{kPa}-50.66 \mathrm{kPa}(0.1 \mathrm{mmHg}-$ $380 \mathrm{mmHg}$ ) at $25^{\circ} \mathrm{C} \mathrm{[6].} \mathrm{National} \mathrm{Emission} \mathrm{Inventory} \mathrm{shows} \mathrm{that} \mathrm{China} \mathrm{has}$ emitted about 16.5 - 23.2 million tons of anthropogenic VOCs from 2005 to 2013, which shows a great amount of pollution [7]. According to the incomplete statistical results of the survey of VOC pollution sources by the Beijing Municipal Environmental Protection Research Institute, typical VOC toxic and hazardous substances mainly come from refinery and petrochemical, oil storage and transportation, paint production and use, printing and ink manufacturing, synthetic rubber, synthetic fiber and other industries, details in Table 1 . As one of the leading factors of PM2.5, VOCs have been gradually attracted attention and become an important part of control of air pollution [8] [9] [10].

The control of VOCs has lasted for more than 30 years in China. However,

Table 1. Major industries VOC hazardous substances.

\begin{tabular}{ccc}
\hline Number & Pollution industries & Typical VOC hazardous substances examples \\
\hline 1 & Refiney and petrochemical & Benzene, 1,3-butadiene, hexane \\
2 & Storage and sales of oil products & Hexane, benzene, toluene, xylene \\
3 & Paint production and use & $\begin{array}{c}\text { Xylene, toluene, benzene, dichloro (chloro), } \\
\text { methane, methyl isobutyl ketone, ethylene glycol }\end{array}$ \\
4 & printing and ink manufacturing & Toluene, xylene, ethylene glycol \\
5 & synthetic rubber & Toluene, xylene, benzopyrene \\
6 & synthetic fiber & Formaldehyde, benzene \\
\hline
\end{tabular}

The information is provided by the Institute of Air Pollution Prevention and Control of Beijing Municipal Academy of Environmental Sciences. 
waste gas control focused on dust removal, desulfurization and denitration all through, leading the low speed development on VOCs' control. The main reason is the lack of control standards and monitoring specifications [9]. The Ministry of Environment protection of the People's Republic of China has published VOC emission standards for 14 industries, including petroleum refining, petrochemicals, coal chemical industry, dry cleaning industry, electronic industry, textile printing and dyeing, printing and packaging, pesticides, pharmaceuticals, coatings, wood-based panels, tank pipes, painting and casting [11] [12] [13]. Meanwhile, it is also accelerating the research and development of VOC emission charging methods and measures. The VOC pollution fees has been charged in the petrochemical industry since 2015. The coal chemical industry, which is also a main VOC emission source, will also be charged of the VOC pollution fees soon.

According to the experience of petrochemical companies in the United States, the part of fugitive emission that comes from equipment leakage is the largest VOC emission source. USEPA National Executive Investigation Center published that VOC emission caused by equipment leakage far exceeds those of container storage, wastewater treatment, transfer operations, ventilation and air exchange, etc., while the leakage from valves and interfaces accounts for more than $90 \%$ of total leakage emission. According to the estimation of USEPA, the emission from equipment leakage accounts for approximately $0.01 \%$ of refinery crude oil processing capacity. The huge amount of leakage not only brings potential risks to the production site, but also is a huge waste of resources [14].

Thus, it can be seen that the implementation of the plant-wide self-inspection on VOCs will greatly help factories and enterprises discover potential safety hazards in advance, improve process safety and reliability, detect equipment leakage in advance, reduce maintenance costs, optimize quality management of equipment suppliers, and guide equipment selection, reduce the risk of exposure to hazardous chemicals [15], reduce air pollution, achieve clean production [16], reduce raw materials and product losses and increase economic benefits.

\section{VOC Management Status}

China's VOC management can be divided into intentional emission and fugitive emission [17]. The VOCs that from intentional and emitted in the coal chemical and petrochemical production processes are easy to identify and can be controlled by installing corresponding monitoring instruments and control devices at the emission outlets [18]. As early as the 1970s, western have promoted the application of oil and gas recovery technologies and formulated strict regulations on hydrocarbon emission. China started the formulation of laws and regulations same as that in developed countries. However, over the years, China has gone through a period of technical exploration. At present, based on the proven technology of the introduction and recovery of self-owned oil and gas, China intends to further strict the regulations on hydrocarbon gas emission [19], which will 
have a major impact on the entire oil and gas recovery market.

Fugitive VOC emission points are scattered and relatively large in the range of concentration changes. With the large size of unit and the rapid development of factory production, these fugitive VOC leakage problems have attracted more and more attention. Leakage is not only causes material loss and environmental pollution, but also can lead to heavy casualties and damage accidents. The research shows that leakage emission from pipeline components and storage tanks accounts for approximately $76 \%$ of total emission of VOCs in the coal chemical and petrochemical industries.

With regard to the fugitive leakage status in the chemical industry, western countries generally adopt the Leak Detection and Repair (LDAR) Technology as a basis to control emission, directly detect the possible leakage and emission points of pipeline components, identify components with potential leakage in time and repair or replace them to achieve the goal of leakage emission reduction [20] [21]. Due to different energy structures, research and application in western countries mainly focus on the petrochemical industry. At present, there is no special research on LDAR in the coal chemical industry in China or abroad.

There is no scientific technology standard system for the direct monitoring technology of fugitive emission like domestic equipment leakage. Thus, it is impossible to effectively monitor VOC emission caused by leakage. Although monitoring specifications for fugitive emission of ambient air are included in the HJ/T55 2000 Technical Guidelines for Fugitive Emission Monitoring of Air Pollutants, as monitoring methods for ambient air at the plant boundary are restricted by several conditions in practical application, desired results cannot be achieved in terms of operability and pollution control.

In 1990, the United States included "Leak Detection and Repair (LDAR)" as The Maximum Feasible Control Technology (MACT) in the amendment of The Clean Air Act, in which LDAR operations must be carried out for petrochemical and chemical enterprises, and leakage detection for equipment (including compressor pressure relief equipment and open pipelines of valve pump sampler) must be carried out to control the fugitive emission of pipeline components. Since then, the LDAR Technology has been adopted by many states and local governments in the United States as one of the measures to meet the United States' atmospheric quality standards.

The United States Environmental Protection Agency (USEPA) promulgated the Protocol for Equipment Leak Emission Estimates in 1993 and updated the Determination of Volatile Organic Compound Leaks (Method 21) in 1995. The LDAR Technology mainly refers to the USEPA Method 21 to determine the leakage components. Method 21 defines the conditions of the leakage detecting instruments (such as the detector response time, response coefficient, etc.) and the detection technique. In addition, Method 21 includes the use of a leakage detecting instrument to move the surface of the potential leakage pipeline components, test VOC concentration, compare the detected VOC concentration value with a na- 
tional or local limit to determine whether there is a leak or need for repair.

It is found in a research from American Petroleum Institute (API) that more than $90 \%$ of leakage emission is easier to control and the emission of only $0.13 \%$ pipeline components is more difficult to control. The research has shown that because the testing cost of each pipeline component in the factory is expensive as required in Method 21, adopting cost-effective methods to locate a large number of leakage points can reduce substantial monitoring costs. This cost-effective method, called Smart-LDAR, allows multiple leakage components to be inspected simultaneously through long-distance optical imaging, increasing the frequency of monitoring, enabling faster detection of large leakage components and performing repairs. In April 2006, Smart-LDAR was passed in USEPA's laws and regulations. After several years of development exploration and practice, this new technology already has the advantages of rapid and cost-effective detection of leakage. When the leakage of pipeline components exceeds a certain value, an operator can clearly see the leakage image. Currently, the United States and Canada are actively introducing this technology and exploring ways to implement and manage LDAR technology economically and effectively.

There are 25 federal government standards requiring enterprises or organizations to implement LDAR, and the federal government has included LDAR Technology in the national emission standards for toxic organic pollutants in the organic chemical industry and MACT in the petrochemical industry. The LDAR Technology can be directly applied to the organic chemical industry to meet the needs of practical operations and become a model for multiple state regulations. Many state regulations impose stricter regulations on LDAR than does the federal government, such as Louisiana and Texas.

Many countries and regions (including Canada and the European Union) use the US Method 21 as the basis for the implementation of LDAR Technology.

\section{LDAR Research and Application in China}

China started VOC leakage research since the early 1970s, a large number of researches on "leak-free factories" were conducted, but it developed slowly for a long time [8].

The Environmental Protection Law of the People's Republic of China was promulgated on December $26^{\text {th }}, 1989$ and its latest revision was on January $1^{\text {st }}$, 2015. The Cleaner Production Promotion Law of the People's Republic of China was promulgated on June $29^{\text {th }}, 2002$ and its revision came into effect on July $1^{\text {st }}$, 2012. Based on the above two laws, the Ministry of Environmental Protection of the People's Republic of China has successively issued a series of regulations and standards, except the leakage management of the chemical production process.

Beijing Municipal Environmental Protection Bureau promulgated a local standard for the control of volatile organic pollutants in 2007, such as the Emission Standard for Air Pollutants in Oil Refining and Petrochemical Industries (DB11/447-2007), in which studies from western standards of equipment leakage monitoring. 
The General Office of the State Council forwarded the Guiding Opinions on Advancing Joint Air Pollution Prevention and Control to Improve Regional Air Quality (GFB [2010] No.33), VOC pollution control has become the focus of environmental protection. VOC control in Beijing, Shanghai, Guangzhou is at the forefront of China and its requirements have been defined through the formulation of a series of standards [22].

Shanghai Environmental Protection Bureau issued the Technical Regulations for Control of VOC Emission from Equipment Leakage (Trial) in August 2014, in which the implementation method and detection frequency of the control technology (leak detection and repair) for the VOC emissions from equipment leakage are stipulated, leakage concentration control limit is defined and implementation result declaration requirements for the leak detection and repair of equipment are clarified. And it is currently LDAR standard with the most practical implementation reference value in China. However, LDAR control standards and operational requirements are still not as strict as USEPA standards.

In accordance with the Circular of State Council on Printing and Distributing Action Plan for Prevention and Control of Atmospheric Pollution (GF [2013] No. 37), VOCs are included in the relevant requirements for charging of pollution fees. The Ministry of Finance, the Ministry of Environmental Protection and the National Development and Reform Commission planned to jointly promulgate the Pilot Scheme for Charging of Pollution Fees of VOCs, which was piloted from January $1^{\text {st }}, 2015$. Subsequently, VOC pollution fee policies are officially implemented throughout China. The first batch of pilots is incorporated in the oil refining and chemical industry and the intentional and fugitive emissions of VOCs are separately monitored and calculated.

China Petrochemical Corporation promulgated the corporate standard Specification for Leak Detection of VOCs from Petrochemical Plants (Q/SH0456-2012) on February $2^{\text {nd }}, 2012$, in which leak detection methods for VOCs in the production process of petrochemical plants are stipulated and corresponding regulations for the instruments and equipment, personnel requirements, detection and implementation, detection safety, quality control, detection reports and others for the detection of volatile organic compounds with different types of leak sources are provided. And the Specification is applicable to the detection of VOCs with various seal point leaks in the production process of petrochemical plants. Some companies have tentatively carried out a variety of leak detection activities according to their specific processes, equipment and materials, and have achieved certain results in the odor treatment or emission reduction. However, there is still a large gap compared with the level of leakage control in the United States, which is mainly manifested in:

1) Device leakage rate is high and the average leakage rate per factory is nearly 30 times that of the United States;

2) Severe leakage rate is high, and the frequency exceeding the range of conventional inspection instruments is nearly 100 times that of the United States; 
3) Open pipelines are in lack of control requirements, leakage is serious and the number of open pipelines is small, but the leakage exceeds $1 / 3$ of the total;

4) After the discovery of the emission source, there is a lack of confirmation and implementation of the repair period; and

5) Due to a small number of enterprises that have tried to develop LDAR and lack standardization, basic data is insufficient and it is of little significance to take domestic enterprises as reference and guidance.

\section{Characteristics of Production and VOC Emission in Coal Chemical Industry}

The coal chemical industry is an industry in which coal energy is comprehensively utilized through chemical processing. The coal chemical industry and petrochemical industry seem to be different chemical industries under two completely different resource conditions, but the process routes and key technologies between them are similar. Coal chemicals and petrochemicals are mainly used to produce fuels and chemical raw materials [23]. The types of their equipment are similar, mainly including pipes, valves, towers, pumps, heat exchangers and compressors. The medium is mainly gaseous and liquid. Control system and power system are similar. The main process flow of the coal chemical industry is shown in Figure 1.

Coal is a composed of complex organic and inorganic substances. To convert a complex and unclean substance through multiple processes of physical and

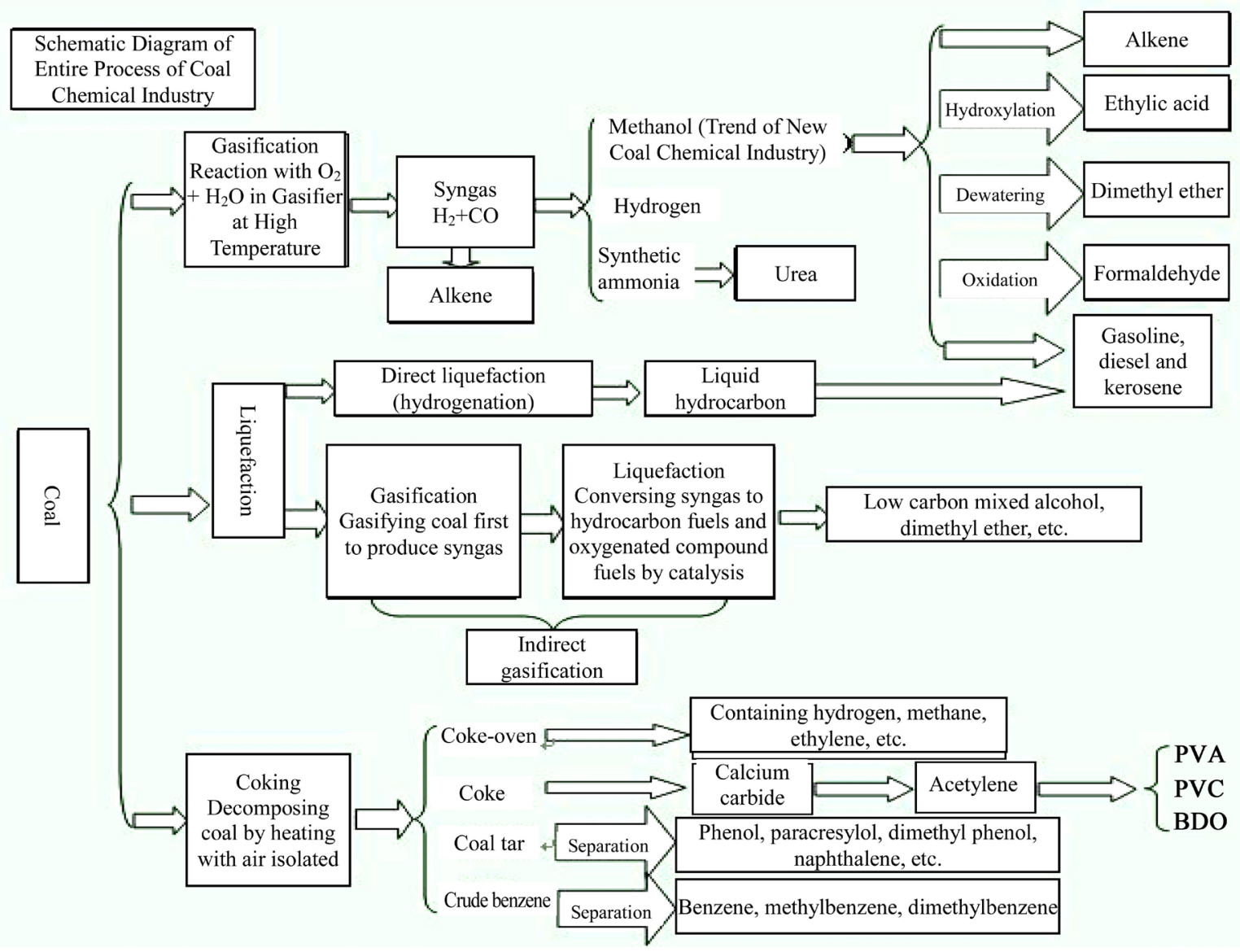

Figure 1. The main process of the coal chemical industry. 
chemical processing into clean energy and chemical products, some pollutants will inevitably be produced [24]. Air pollutants produced by coal chemical projects mainly come from the intentional emission of tail gas from coal preparation and gasification, purification, transformation, synthesis and refinement, as well as fugitive emission of VOCs from the production process, intermediate material tanks and finished product tank respiration. Major pollutants include large amounts of VOCs, dust, smoke, $\mathrm{NO}_{\mathrm{X}}, \mathrm{H}_{2} \mathrm{~S}, \mathrm{SO}_{2}, \mathrm{CO}, \mathrm{CO}_{2}, \mathrm{HCN}$, etc.

\section{VOC Self-Inspection Management Scheme}

\subsection{Overall Framework}

From the development of advanced VOC control in western countries, the overall development trend is the gradual standardization and professionalization of inspection and management. Standardization is set up based on laws and regulations, technical specifications, it requires enterprises to pay attention on VOC emission and solve emission problems. Professionalization is that inspection and management work completed by professional technical service agencies, evaluated current enterprises VOC emission status by using advanced scientific detection systems and equipment, in addition of making countermeasures and solutions to the problems are proposed. Details are shown in Figure 2.

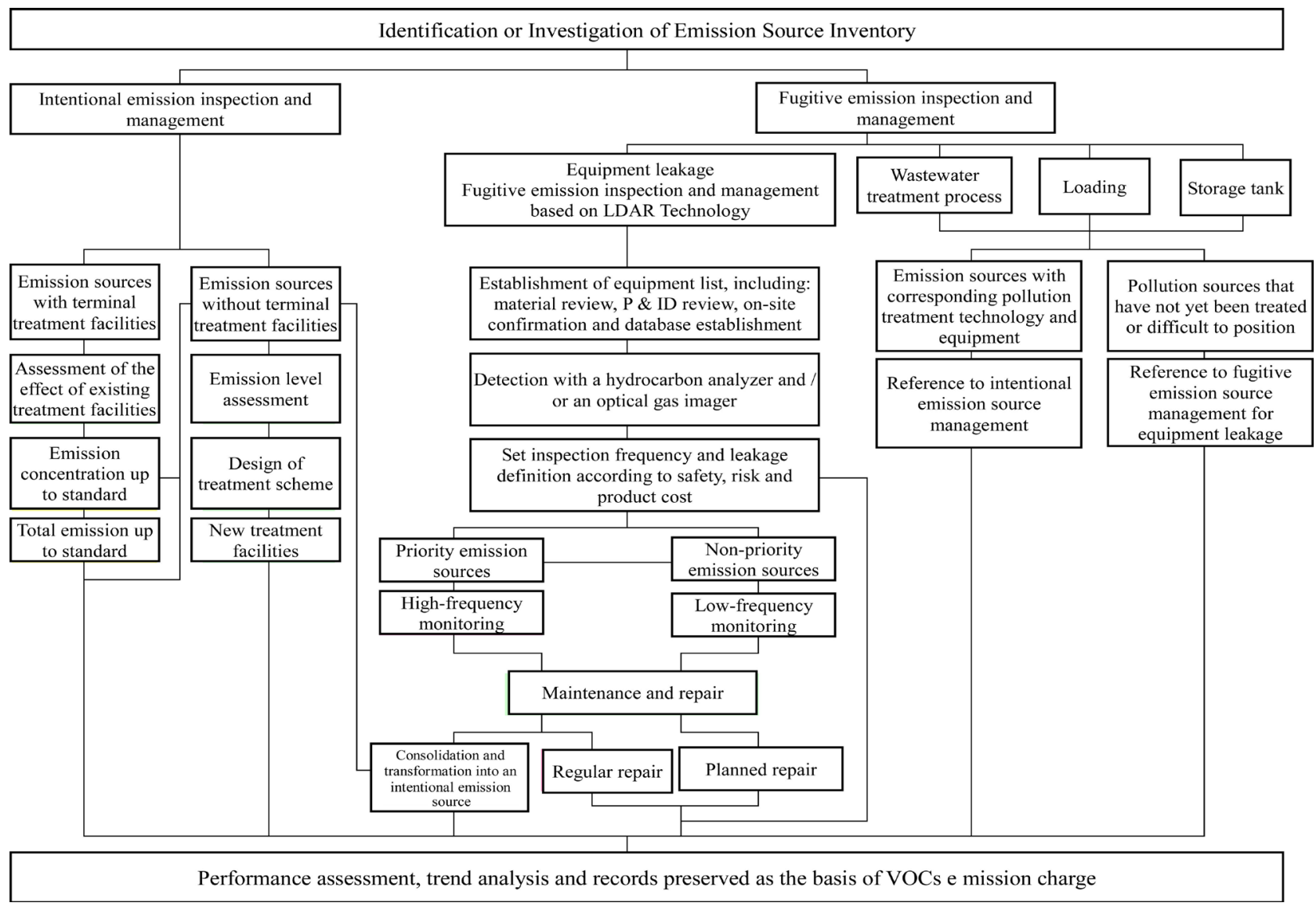

Figure 2. Overall framework of plant-wide VOC inspection and management scheme. 


\subsection{Scheme Steps}

\subsubsection{Identification or Investigation of Emission Source Inventory}

According to the production process of the plant to be inspected, the first step of the inspection scheme is to conduct a survey for the plant-wide production process and prepare an inventory of production systems, devices and pipelines that may generate VOC emission. The common production processes of the coal chemical industry mainly include:

- Coal preparation system;

- Gasification system;

- Purification, transformation and recovery systems; and

- Sewage treatment system.

Coal preparation system mainly produces dust and particulate pollution, and other systems produce mixed waste gas such as VOCs, particulate matter, nitrogen and sulfur, with both intentional and fugitive emissions.

\subsubsection{Judgement and Assessment of Emission Source Inspection and Management Scheme}

According to the conclusions obtained from the identification or survey of emission inventories, management measures for emission sources shall be analyzed accordingly, comprehensive consideration shall be given to investment income, project planning, emission reduction cost and control efficiency, the most appropriate management scheme shall be assessed and determined.

\subsubsection{Implementation of Emission Source Inspection and Management Projects}

According to a prepared inventory of production systems, devices, pipelines, etc., clearly intentional emission points should be located, and VOC emission and control status of these intentional emission points should be assessed. This part of the work is relatively easy to identify. The general intentional emission points are waste gas and tail gas outlets of the production equipment. China has a comprehensive standard and supervision system. Self-Inspection can be carried out a control effect assessment and an emission level assessment on the intentional emission sources that have been equipped with terminal control facilities and the emission sources that have not yet been equipped with terminal control facilities. The emission sources that have already been equipped with terminal control facilities but whose control effects do not meet the standard should be deemed to those that have not yet been equipped with terminal control facilities. Necessary control schemes should be designed and control facilities should be constructed.

Inspection of fugitive emission is the core task of the overall inspection scheme, which is to compile a fugitive emission list in the plant-wide production process. The fugitive emission of VOCs in the production of chemical plant-wides includes:

- Fugitive emission from equipment leakage; 
- Fugitive emission from wastewater treatment process [25];

- Fugitive emission from loading operation; and

- Fugitive emission from storage tanks.

In recent years, through the promulgation and implementation of supporting regulations and the promotion and use of new equipment and new technologies, fugitive emissions from waste water treatment process, loading operations and storage tanks can be controlled effectively. However, there was no obvious control effect for fugitive emission of VOCs from equipment leakage, which is one of the reasons for foul odor generated in the chemical production area. The most important is to identify leakage in various parts of pipeline component equipment (pumps, valves, fittings, etc.), which is the largest VOC emission source in the chemical production process according to USEPA research results. The leakage of VOCs caused by equipment leakage far exceeds that from container storage, sewage treatment, transfer operations, ventilation, etc., while the leakage of valves and interfaces accounts for more than $90 \%$ of the total leakage. In a typical coal chemical plant, there might be hundreds of devices that can leak, and how to quickly determine the leakage source is the key to implementing control.

Fugitive emission inventory can be optimized based on the most advanced LDAR technology in the world and combined with years of waste gas control experience. A complete work scheme may include at least the following steps and content:

Step 1: Establishing an equipment inventory, including material review, P\&ID review, site confirmation and database establishment

Equipment that needs to be monitored for fugitive emission during the plant-wide production process should be identified. Each detection component should be identified with a unique identifier (LDAR must be implemented for specific equipment components, which is required in the regulations of the United States). The ID number of the target component in the pipeline and equipment drawings (like P \& ID drawing) should be marked, LDAR data with electronic equipment shall be recorded, brands shall be hung at site or bar codes shall be used for leakage components to achieve digital management. A regular on-site inspection shall be performed to ensure that a strict correspondence between all equipment components and IDs shall be always maintained during the pant production process.

Step 2: Detecting with hydrocarbon analyzers and/or optical gas imagers, and setting inspection frequency and leak definition based on safety, risk and product cost

There are no specific regulations for fugitive emission of VOCs from the coal chemical industry in China. Experiences learn from the existing standards in other cities (like Shanghai) and other industries (like petrochemical industry). Standard regulations that USEPA applies LDAR management to the chemical industry, combined with the management and control objectives to determine the emission concentration standards for various types of equipments that gen- 
erate fugitive emission of VOCs. Generally, factories adopt more stringent emission standards than regulatory requirements. When multiple standards exist, the most stringent standards are recommended.

Leak detection technology was start from visual and acoustical check, later technology developed to use a soap film for leak detection (at present, a large part of China's petrochemical enterprises still use this technology), and further developed to use a portable detector for leak detection. Due to the continuous improvement of environmental protection management requirements and the implementation of new environmental protection standards, the most mature and widely used technology in developed countries is the leak detection. In recent years, technologies that using infrared light imaging to assist in leak detection have also been developed.

A detector is used to detect surfaces of equipment that may leak. If the reading of the detector is found to be large and has an upward tendency, tracking its surrounding area should continued, the detector needs to be placed at the highest reading and set up an reasonable frequency to read the instrument response. Then, the maximum recorded value will be marked as the leak value monitored here. If the concentration of one unit of equipment exceeds the standard value, it indicates that the equipment is leaking and needs to be repaired or modified. The monitoring period of equipment components varies, and the monitoring frequency of the plant is generally higher than that specified by regulations.

\section{Step 3: Maintenance and repair}

With reference to the United States's New Source Performance Standards (NSPS): Once one set of equipment is found to be leaking, it must be repaired within $5 \mathrm{~d}$. The repair time must not exceed $15 \mathrm{~d}$. It can be repaired with leak-free components or other technologies. The leaked components shall be monitored in time to ensure the equipment can be repaired successfully. Delayed repairs can only be performed under certain uncontrollable conditions, but the delayed repairs must be documented, with the specific time for the delayed repairs noted.

1) Fugitive emission sources with large scale and large potential safety hazards shall be identified and listed as priority; other fugitive emission sources are non-priority;

2) For fugitive emission sources listed as priority, the possibility of merging or transforming into intentional emission sources shall be considered first and a pollution control device shall be installed to simplify the follow-up monitoring and management. For fugitive emission sources that cannot be merged or transformed, a regular repair plan shall be formulated;

3) For fugitive emission sources listed as non-priority, corresponding repair and regular inspection plans shall be formulated in accordance with production planning, technology upgrade plans and regulatory requirements;

4) After the repair of priority and a period of continuous monitoring, if the leakage status is controlled within the standard range, the priority can be re- 
duced to non-priority management to reduce unnecessary management costs;

5) With the continuous improvement of national and industry standards and continuous development of technology, some non-priority may need to be upgraded to priority management to ensure that the emission level of the entire plant meets the standards within the control range.

\subsubsection{Performance Evaluation and Trend Analysis}

In this step, not only the monitoring and repairing of fugitive emissions from equipment leakage, but also the monitoring and treatment of emission of other VOCs within the plant-wide inspection and management scope, need to be recorded and saved. The accumulated data will be the valuable basic empirical data for the coal chemical industry in China to carry out LDAR and plant-wide VCO inspection and management, and will also provide an important decision-making basis for China's coal chemical industry to implement VOC pollution fees.

Corresponding data should be recorded and reported. The database keeping records is include all target components to be monitored, components with special design or monitoring exemptions, all monitored and repaired data, etc. With reference to the United States' regulations, leak detection and repair shall be reported 2 times per year. The report includes the number of leaked pumps per month, number of valves, compressors, unrepaired components within 15 days, reasons for delayed repairs, and a list of records resulting from the closing of operation units due to repair, a detailed list of replaced components, etc. Through the classified evaluation of the equipment tightness according to type, supplier, chemical material and process conditions, a decision-making basis for equipment maintenance and upgrade can be provided. Relying on the repair efficiency/repair success rate, a decision-making basis for follow-up tracking and implementation measures can be provided.

\section{Benefits Expected from Implementation of Plant-Wide VOC Self-Inspection and Management}

According to the research results of the USEPA (source: USEPA LDAR Best Practice Guide), a conventional petrochemical and chemical plant (equipped with over 20,000 equipment components in total), can cause VOC emission up to $600 \mathrm{t}$ to $700 \mathrm{t}$ through equipment leakage from valves, fittings, pumps, sampling joints, compressors, pressure release devices, open end pipelines and others each year (see Table 2). Among them, the leakage caused by valves and fittings accounts for more than $90 \%$ of the total equipment leakage.

If components with a detection result of more than $10,000 \mathrm{ppm}$ are repaired, about $70 \%$ of emission can be reduced. If components with a detection result of more than $500 \mathrm{ppm}$ are repaired, about $90 \%$ of emission can be reduced, which will bring greater economic benefits.

Self-inspection can bring other benefits such as detecting safety hazards in advance improving process safety and reliability. Detecting equipment leakage in advance and reducing maintenance costs as well. On the other hand, optimizing 
Table 2. Fugitive emissions in typical petrochemical and chemical plants.

\begin{tabular}{ccc}
\hline $\begin{array}{c}\text { Quantity of equipment components associated with fugitive emissions in typical petrochemical and } \\
\text { chemical plants [26] }\end{array}$ & Average quantity \\
\hline Component & Quantity range & 100 \\
\hline Pump & $10-360$ & 7400 \\
Valve & $600-60,000$ & 12,000 \\
Fitting & $1-1600$ & 560 \\
Open end pipeline & $20-200$ & 80 \\
Sampling joint & $5-360$ & 90 \\
Pressure release valve & 19 & 3 \\
\hline VOCs fugitive emission without LDAR control in typical petrochemical and chemical plants [26] \\
\hline Component & Annual average VOC emission (t/a) & Proportion (\%) \\
\hline Pump & 408 & 62 \\
Valve & 201 & 31 \\
Fitting & 9 & 1 \\
Open end pipeline & 11 & 2 \\
Sampling joint & 5 & 1 \\
Pressure release valve & 653 & - \\
Total & 9 & 3
\end{tabular}

quality management of equipment suppliers and guiding equipment selection; reducing the risk of exposure to harmful chemicals, reducing air pollution and achieving cleaner production; reducing the loss of raw materials and products and increasing economic returns are potential benefits from self-inspection. Before one country fully implements VOC pollution fees, it is necessary to understand its own emission status, understand the cost of pollution discharge and find the most appropriate emission reduction plan.

\section{Recommendations for Implementation}

Take an overall consideration for the current domestic and international regulations, standards and technical development backgrounds for VOC inspection and management. It is beginning with deploy and implement the VOCs plant-wide self-inspection and management from the following points (Table 3):

Step 1: Establish strategic partnerships with industry-leading technology, service and product suppliers, jointly form a special group for "VOC inspection and management", conduct an in-depth study of relevant regulations, standards and technologies, formulate an action framework for corporate VOC inspection and management and incorporate it into the annual corporate development plan.

Step 2: Identify or survey VOCs emission inventories, and adopt calculations or measurements to determine appropriate emission factors, evaluate the overall project volume and carry out necessary emission source detection and equipment 
Table 3. Procedures of recommendations for implementation.

\begin{tabular}{ll}
\hline Steps & \multicolumn{1}{c}{ Contents } \\
\hline 1 & $\begin{array}{l}\text { Establish strategic partnerships with industry-leading technology, service and product } \\
\text { suppliers, jointly form a special group for "VOC inspection and management", conduct } \\
\text { an in-depth study of relevant regulations, standards and technologies, formulate an } \\
\text { action framework for corporate VOC inspection and management and incorporate it } \\
\text { into the annual corporate development plan. }\end{array}$ \\
& Identify or survey VOCs emission inventories, and adopt calculations or measurements \\
to determine appropriate emission factors, evaluate the overall project volume and carry \\
out necessary emission source detection and equipment leakage detection according to \\
specific requirements and circumstances. \\
Formulate and evaluate the corresponding inspection and management measures for \\
intentional and fugitive emission sources respectively according to the establishment of \\
VOC emission inventory. \\
Carry out the corresponding inspection and management projects of intentional and \\
fugitive emission sources respectively according to the measures determined by the \\
assessment.
\end{tabular}

leakage detection according to specific requirements and circumstances.

Step 3: Formulate and evaluate the corresponding inspection and management measures for intentional and fugitive emission sources respectively according to the establishment of VOC emission inventory.

Step 4: Carry out the corresponding inspection and management projects of intentional and fugitive emission sources respectively according to the measures determined by the assessment.

\section{Summary}

It is essential to self-inspect the VOC emission in China's traditional energy chemical industry. By learning from the implementation and management methods of LDAR Technology of the United States, the self-inspection scheme specifically includes the identification or survey of emission inventory, judgment and assessment of emission source inspection and management scheme, implementation of emission source inspection and management projects, performance evaluation and trend analysis. Not only can this method achieve VOC emission reduction and increase economic efficiency, but also reduce costs and achieve cleaner production.

\section{Acknowledgements}

This project is financially supported by State Key Joint Laboratory of Environment Simulation and Pollution Control.

\section{Conflicts of Interest}

The authors declare no conflicts of interest regarding the publication of this paper. 


\section{References}

[1] Han, S., Chen, H., Long, R. and Cui, X. (2018) Peak Coal in China: A Literature Review. Resources, Conservation and Recycling, 129, 293-306.

https://doi.org/10.1016/j.resconrec.2016.08.012

[2] Yuan, J. (2018) The Future of Coal in China. Resources, Conservation and Recycling, 129, 290-292. https://doi.org/10.1016/j.resconrec.2016.12.006

[3] Zou, C., Zhao, Q., Zhang, G. and Xiong, B. (2016) Energy Revolution: From Fossil Energy to New Energy. Natural Gas Industry, 36, 1-10.

[4] Cheng, J., Zhang, Y., Wang, T., Xu, H., Norris, P. and Pan, W.-P. (2018) Emission of Volatile Organic Compounds (VOCs) during Coal Combustion at Different Heating Rates. Fuel, 225, 554-562. https://doi.org/10.1016/j.fuel.2018.03.185

[5] Xue, Y. (2013) A Review of the Development of China's Coal Industry. Journal of China University of Mining \& Technology, 15, 87-94.

[6] Center for Environmental Research Information, Office of Research and Development, US Environmental Protection Agency (EPA) (1997) Compendium Method TO14A/TO15. EPA, Cincinnati.

[7] Zhang, Z., Wang, H., Chen, D., Li, Q., Thai, P. and Gong, D. (2017) Emission Characteristics of Volatile Organic Compounds and Their Secondary Organic Aerosol Formation Potentials from a Petroleum Refinery in Pearl River Delta, China. Science of the Total Environment, 584-585, 1162-1174.

[8] Chen, Y., Li, L., Yang, C., Hao, Z., Sun, H. and Li, Y. (2011) Study on the Priority Control Countermeasures of VOC Toxic Air Pollutants in China. Environmental Science, 32, 3469-3475.

[9] Liu, N. (2013) Discussion on the Relationship between VOC Emissions of Industrial Coatings and PM2.5. Science and Technology Innovation Review, No. 22, 73-74.

[10] Han, D., Gao, S., Fu, Q., Cheng, J., Chen, X., Xu, H., Liang, S., Zhou, Y. and Ma, Y. (2018) Do Volatile Organic Compounds (VOCs) Emitted from Petrochemical Industries Affect Regional PM2.5? Atmospheric Research, 209, 123-130.

[11] Chen, Y., Dai-Qi, Y.E., Liu, X.Z., et al. (2012) Characteristics and Source-Tracing of Industrial VOCs Emissions in China. China Environmental Science, 32, 48-55.

[12] Bao, Y., Xu, P., Cai, S., Yu, H. and Li, X. (2018) Detection of Volatile-OrganicCompounds (VOCs) in Solution Using Cantilever-Based Gas Sensors. Talanta, 182, 148-155. https://doi.org/10.1016/j.talanta.2018.01.086

[13] Cao, G.L., An, X.Q., Zhou, C.H., et al. (2010) Regional Reactive Gas Emissions Inventory in China. China Environmental Science, 30, 900-906.

[14] Lu, P. (2013) Discussion on the Necessity of LDAR Work in Refining and Chemical Enterprises. Petrochemical Safety and Environmental Protection Technology, 29, 21-25.

[15] Hu, R., Liu, G., Zhang, H., Xue, H. and Wang, X. (2018) Levels, Characteristics and Health Risk Assessment of VOCs in Different Functional Zones of Hefei. Ecotoxicology and Environmental Safety, 160, 301-307. https://doi.org/10.1016/j.ecoenv.2018.05.056

[16] Zhang, S., You, J., Kennes, C., Cheng, Z., Ye, J., Chen, D., Chen, J. and Wang, L. (2018) Current Advances of VOCs Degradation by Bioelectrochemical Systems: A Review. Chemical Engineering Journal, 334, 2625-2637.

https://doi.org/10.1016/j.cej.2017.11.014

[17] Yang, L.X. (2012) Study on Temporal-Spatial Characteristic and Control Strategy of 
Industrial Emissions of Volatile Organic Compounds in China. Master's Thesis, South China University of Technology, Guangzhou.

[18] Liu, J.F., Zhao. J., Li, T.T., et al. (2008) The Establish of VOCs Emission Inventory from Anthropogenic Sources in China. China Environmental Science, 28, 496-500.

[19] Liu, Y., Shao, M., Fu, L., Lu, S., Zeng, L. and Tang, D. (2008) Source Profiles of Volatile Organic Compounds (VOCs) Measured in China: Part I. Atmospheric Environment, 42, 6247-6260. https://doi.org/10.1016/j.atmosenv.2008.01.070

[20] Su, S. and $\mathrm{Hu}$, J. (2018) Ultrasound Assisted Low-Concentration VOC Sensing. Sensors and Actuators B: Chemical, 254, 1234-1241. https://doi.org/10.1016/j.snb.2017.07.175

[21] Wang, Q., Li, S., Dong, M., Li, W., Gao, X., Ye, R. and Zhang, D. (2018) VOCs Emission Characteristics and Priority Control Analysis Based on VOCs Emission Inventories and Ozone Formation Potentials in Zhoushan. Atmospheric Environment, 182, 234-241. https://doi.org/10.1016/j.atmosenv.2018.03.034

[22] Yu, Y.F., Lu, Q., Zheng, J.Y., et al. (2011) Industrial VOCs Emissions Inventory in Pearl River Delta Region. China Environmental Science, 31, 195-201.

[23] Tang, X., Jin, Y., McLellan, B.C., Wang, J. and Li, S. (2018) China's Coal Consumption Declining-Impermanent or Permanent? Resources, Conservation and Recycling, 129, 307-313. https://doi.org/10.1016/j.resconrec.2016.07.018

[24] Xu, X., Liu, Y., Zhang, F., Di, W. and Zhang, Y. (2017) Clean Coal Technologies in China Based on Methanol Platform. Catalysis Today, 298, 61-68. https://doi.org/10.1016/j.cattod.2017.05.070

[25] Malakar, S., Saha, P.D., Baskaran, D. and Rajamanickam, R. (2017) Comparative Study of Biofiltration Process for Treatment of VOCs Emission from Petroleum Refinery Wastewater-A Review. Environmental Technology \& Innovation, 8, 441-461. https://doi.org/10.1016/j.eti.2017.09.007

[26] Li, R. (2016) Application of LDAR Technology in Huizhou Petrochemical co., LTD and the VOCs Emission Reduction Effect. Chemical Intermediate, 34-35. 